\title{
SEJARAH HP NOKIA DARI MASA KE MASA
}

\author{
Pathul Khorib \\ 185100030 \\ Fakultas Komputer \\ pathulkhorib.student@umitra.ac.id
}

\begin{abstract}
Kata Nokia berasal dari nama sebuah komunitas yang tinggal di sungai Emakoski di negara Finlandia Selatan. Nokia didirikan sebagai perusahaan penggilingan pulp oleh Fredrik Idestam pada tahun 1865. Perusahaan Karet Finlandia kemudian mendirikan pabriknya di kawasan sekitarnya pada awal abad ke-20 dan mulai menggunakan merek Nokia.

Tak lama setelah usainya Perang Dunia I, Perusahaan Karet Finlandia mengakuisisi Perusahaan Penggilingan Kayu Nokia dan Perusahaan Kabel Finlandia (sebuah produsen kabel telepon dan telegraf). Ketiga perusahaan tersebut digabung menjadi Nokia Corporation pada tahun 1967. Kemudian dikembangkan menjadi mesin bubur kayu dan pembuat kertas pada tahun 1920 dan merupakan pabrik pembuat kertas terkemuka di Eropa.
\end{abstract}

Kata Kunci : Penerimaan dan Pengeluaran Kas.

A. PENDAHULUAN

Kini sebanyak 2.100 seri 
ponsel Nokia mendulang sukses. Target penjualan sebanyak 500 ribu unit berhasil diraih pada 1994. Dengan tenaga kerja sebanyak 54 ribu orang, produk Nokia terjual di 130 negara. Sekarang mungkin setiap orang tahu telepon seluler yang mudah dalam pengoperasiannya adalah Nokia, karena itulah moto Nokia.

Sejak dahulu negara Finlandia sangat tergantung pada hasil hutannya yaitu berupa kayu, seperti yang telah dikatakan oleh salah satu pihak Departemen Luar Negeri Finlandia, Jyrki Vesikansa, "Dulu kami hidup dari hutan, tetapi saat ini kami dapat menambahkan pada Nokia".

Pada tanggal 15 Agustus 2007, Nokia pusat melakukan recall terhadap baterai tipe BL-5C, salah satu baterai terpopuler untuk ponsel Nokia pada saat ini.[4]

Pada tanggal 3 September 2013, Microsoft akan membeli unit bisnis perangkat dan layanan bisnis Nokia senilai 3,79 miliar euro (5 miliar dollar AS) dan 1,65 miliar euro (2,2 miliar dollar AS) untuk lisensi paten Nokia. Jika ditotal, Microsoft harus merogoh kocek 5,44 miliar euro (7,2 miliar dollar AS atau sekitar Rp 79 triliun) untuk rencananya mengakuisisi bisnis utama Nokia.

\section{B. PEMBAHASAN / STUDI KASUS \\ SEJARAH NOKIA}

Dalam sejarah inovasi NOKIA selama 1,5 abad, mulai dari pabrik penggilingan kertas di Finlandia sampai menjadi pemimpin komunikasi global, di bagi menjadi 4 zaman:

\section{Abad Pertama (1865-} 1967)

Nokia abad pertama mulai dengan pabrik kertas Fredrik Idestam di tepi sungai Nokianvirta. Antara 1865 dan 1967, perusahaan akan menjadi kekuatan industri besar, tetapi butuh merger dengan perusahaan kabel dan perusahaan karet untuk mengatur Nokia Corporation baru di jalan menuju elektronik ...

Sejarah Nokia dimulai pada tahun 1865. Saat itulah Fredrik Idestam membangun sebuah pabrik pulp kayu di tepi jeram Tammerkoski, di Finlandia selatan. Beberapa tahun kemudian, ia membangun pabrik kedua oleh sungai Nokianvirta - tempat yang memberi nama Nokia. 
$\begin{array}{lr}\begin{array}{l}\text { Idestam Fredrik } \\ \text { seorang }\end{array} & \begin{array}{r}\text { adalah } \\ \text { insinyur }\end{array} \\ \text { pertambangan } & \text { yang } \\ \text { membawa } & \text { proses }\end{array}$ pembuatan kertas baru yang lebih murah dari Jerman ke Finlandia. Itu ternyata adalah suatu kesuksesan besar. Penemuan Idestam memenangkan medali perunggu di Paris World Exposition tahun 1867, dan ia dianggap sebagai ayah dari industri kertas Finlandia. 1871: Idestam menamai perusahaannya "Nokia Ab". 1898: Finnish Rubber Works didirikan

Eduard Polon mendirikan Finnish Rubber Works, yang kemudian akan menjadi bisnis karet Nokia.

1902: Nokia Ab menambahkan pembangkit listrik untuk kegiatan usahanya.

1912: Finlnish Cable Works didirikan

Arvid Wickström memulai Finnish Cable Works, dasar dari kabel Nokia dan bisnis elektronik.

1937: Mantan atlet gulat Olimpiade Verner Weckman, menjadi Presiden Finnish Cable Works.

Pada tahun 1937, Verner Weckman menjadi Presiden dari salah satu pendiri perusahaan Nokia Corporation, Finnish Cable Works, setelah 16 tahun sebagai perusahaan Direktur Teknik.

Weckman sebelumnya telah bekerja sebagai seorang insinyur pertambangan di Rusia pada tahun 1909-1921. Pengetahuan tentang bahasa Rusia dan budaya, serta sambungan industrinya, terbukti penting ketika Finnish Cable Works mulai produk ekspor ke Uni Soviet setelah Perang Dunia Kedua.Weckman juga seorang pegulat kelas ringan tingkat dunia dan orang Finlandia pertama peraih medali emas Olimpiade.

la memenangkan Kejuaraan Dunia gulat pada tahun 1905 Dia memenangkan medali emas Olimpiade di gulat pada Olimpiade 1906 di Athena dan di London 1908 Games

Tahukah Anda?:

Finnish Cable Works menyediakan kabel ke Uni Soviet sebagai bagian dari reparasi perang Finlandia setelah Perang Dunia II. Hal ini memberikan perusahaan pijakan yang baik untuk perdagangan nanti

1960: Cable Works mendirikan perusahaan departemen elektronik pertama, menjual dan mengoperasikan komputer.

Departemen elektronik:

Finlandia Cable Works, sudah bekerja sama dengan Nokia $A b$ dan Finnish Rubber Works, bercabang ke 
elektronik di tahun 1960-an. Pada tahun 1962, mereka membuat perangkat elektronik pertama dalam rumah: penganalisis getaran yang dirancang untuk digunakan dalam pembangkit listrik tenaga nuklir .

Keterlibatan perusahaan dengan sistem telekomunikasi juga dimulai pada tahun 60an, dan tahun 1963 mulai mengembangkan telepon radio untuk tentara dan layanan darurat.

Departemen elektronik pergi untuk menjual komputer mainframe dan menjalankan pusat komputer untuk melayani kebutuhan perusahaan TI.

Nokia kemudian membuat:

1. TV - pada tahun 1987 Nokia akan menjadi produsen TV terbesar ketiga di Eropa

2. Komputer - yang MikroMikko menjadi merek komputer terkenal di Finlandia telepon radio

3.Ttransfer data peralatan

4. Radio link dan analisa

5. pertukaran telepon digital

Nokia mungkin meninggalkan konsumen elektronik pada tahun 1990an. Namun keahlian telekomunikasi yang dikembangkan dari tahun 1960-an dan seterusnya akan menjadi inti dari kerja di masa depan.

1967: Nokia Ab, Finnish Rubber Works dan Finnish Cable Works bekerja secara resmi bergabung untuk menciptakan Nokia Corporation .

Tiga perusahaan yang bergabung menciptakan Nokia Corporation adalah:

Nokia Ab, Finnish Cable Works, dan Finnish Rubber Works

Perusahaan yang telah dimiliki bersama sejak tahun 1922, resmi bergabung pada tahun 1967. Pada saat itu, Nokia $A b$ adalah yang terkecil dari tiga tersebut. Saat itu Nokia Corporation baru memiliki lima bisnis: karet,kabel,kehutanan,elektr onik,pembangkit listrik

Setiap bisnis memiliki direktur sendiri yang melaporkan kepada Presiden pertama Nokia Corporation, Björn Westerlund . Sebagai presiden Pekerjaan Kabel Finlandia, ia telah bertanggung jawab untuk menyiapkan perusahaan elektronik pertama departemen , menabur benih -benih itu masa depan Nokia di telekomunikasi.

2. Berpindah ke mobile: 1968-1991

Terbentuk Nokia baru 


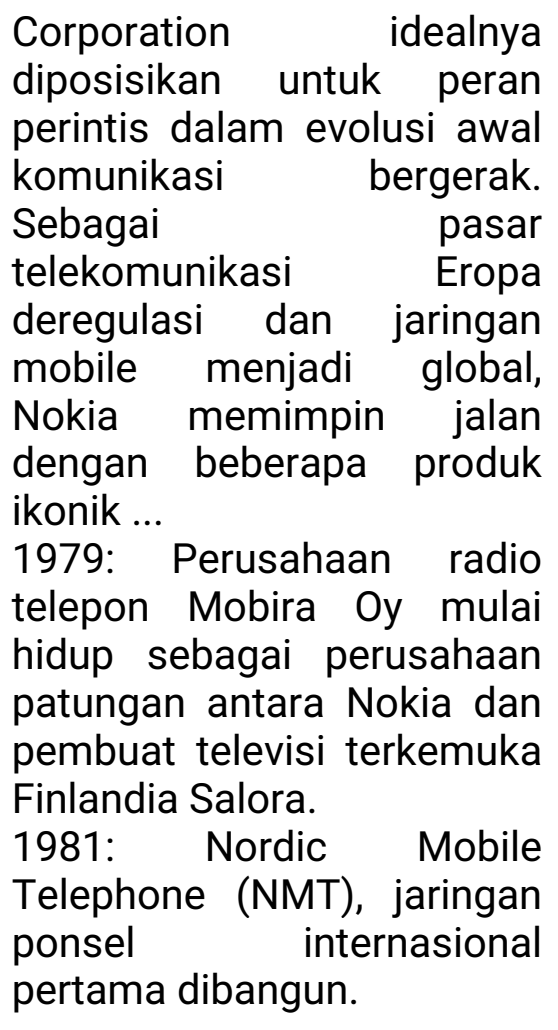

Sebuah era baru untuk ponsel mulai tahun 1981, dengan peluncuran layanan Nordic Mobile Telephone (NMT).

Awalnya mencakup beberapa negara-negara Nordik, layanan yang pertama di dunia dengan jaringan selular internasional . Itu juga yang pertama untuk memungkinkan roaming internasional , dan tertangkap di dalam maupun di luar Eropa.

Dengan diperkenalkannya standar NMT, industri telepon seluler mulai berkembang pesat.

Nokia segera memperkenalkan telepon mobil pertama ke jaringan.
The Mobira 450 telepon mobil datang pada tahun 1982, diikuti oleh portabel di 1986. Pada saat ini perusahaan juga menyediakan base station dan switch untuk operator jaringan NMT.

Tahukah Anda?:

Walaupun nokia mengambil bisnis telekomunikasi, tetep bisbi kabel dan karetnya masihlah kuat. Salah satu kesuksesan besar di awal 1970an adalah Kontiosepatu karet yang tersedia dalam berbagai warna dan cocok untuk segala umur.

1982: Nokia membuat saklar digital telepon pertama

The Nokia DX200, digital switch telepon perusahaan pertama, masuk ke dalam operasi.

1984: Nokia meluncurkan ponsel Mobira Talkman portabel.

1987: Nokia meluncurkan Cityman Mobira, telepon genggam NMT pertama.

Ponsel pada zaman itu bentuknya berat, besar dan biasanya permanen terpasang di mobil.

Tapi pada 1987 membuat terobosan: Nokia meluncurkan Cityman Mobira, ponsel genggam pertama untuk jaringan NMT dan model yang menjadi klasik.

Ponsel Nokia mendapat 
dorongan publisitas besar pada tahun 1987, ketika pemimpin Uni Soviet Mikhail Gorbachev digambarkan menggunakan Cityman untuk membuat panggilan dari Helsinki untuk melayani komunikasi di Moskow. Hal ini menyebabkan kasih sayang nama panggilan telepon dari "Gorba".

The Cityman Mobira 900 beratnya sekitar 800 gram dan memiliki tag harga 24.000 Marks Finlandia (sekitar USD 4.560).

1991: GSM - sebuah standar mobile baru dibuka

Peralatan Nokia yang digunakan untuk membuat panggilan GSM pertama dunia.

Pada tanggal 1 Juli 1991, Perdana Menteri Finlandia Harri Holkeri membuat panggilan GSM pertama di dunia , dengan menggunakan peralatan Nokia.

Itu adalah pilihan yang tepat. Sejak awal, Nokia adalah salah satu pengembang kunci dari teknologi GSM. Itu keahlian dalam standar baru , ditambah dengan deregulasi pasar telekomunikasi Eropa di tahun 1980-an dan 1990-an, adalah menjadi titik tolak kesuksesan internasional. Spoiler for Apa itu GSM?:
The Global System for Mobile communications (GSM) diadopsi pada tahun 1987 sebagai standar Eropa untuk teknologi mobile digital . Ponsel ini teknologi generasi kedua bisa membawa data serta lalu lintas suara. Panggilan suara berkualitas tinggi, roaming internasional yang mudah dan dukungan untuk layanan baru seperti pesan teks (SMS) meletakkan dasar-dasar untuk sebuah ledakan di seluruh dunia dalam menggunakan telepon selular.

Nokia berada di garda depan pembangunan di GSM, memberikan perusahaan jaringan GSM pertama untuk Finlandia Radiolinja perusahaan pada tahun 1989. Nokia meluncurkan digital genggam telepon GSM pertama , Nokia 1011, pada tahun 1992.

Pada akhir 1990-an, Nokia telah memasok sistem GSM untuk lebih dari 90 operator di seluruh dunia.

Tahukah Anda?:

Nokia adalah produsen pertama yang membuat seri ponsel portable genggam untuk semua standar digital utama , termasuk TDMA PCN dan Jepang Digital, serta GSM.

3. Revolusi Mobile (19921999) 
Pada tahun 1992, Nokia memutuskan untuk fokus pada bisnis telekomunikasi. Ini mungkin keputusan strategis yang paling penting dalam sejarah.

Sebagai penerapan pertumbuhan standar GSM, CEO baru Jorma Ollila menempatkan Nokia di kepala booming global industri telepon mobile - dan membuatnya menjadi pemimpin dunia sebelum akhir dekade ...

1992: Jorma Ollila menjadi Presiden dan CEO Nokia, memfokuskan perusahaan pada telekomunikasi.

Bagaimana telekomunikasi menjadi inti Nokia:

Ketika Jorma Ollila menjadi Presiden dan CEO Nokia pada tahun 1992, perusahaan membuat keputusan strategis penting : untuk fokus pada telekomunikasi dan keluar dari bisnis lainnya.

Selama tahun 1990-an, karet, kabel dan elektronik konsumen divisi secara bertahap dijual sebagai perusahaan pindah ke berkonsentrasi pada komunikasi. bisnis inti Nokia sekarang:

1. manufaktur ponsel

2. manufaktur sistem telekomunikasi

Strategi ini untuk membuktikan sukses besar, karena visi Jorma Ollila jangka panjang Nokia didorong ke panggung dunia.

\section{ID SECURITY QWTD4452377-ASP- 5244107}

\section{KESIMPULAN}

Inovasi teknologi yang tak terkendali, demikian juga dengan hukum alam yang satu ini, bahwa roda terus berputar, setelah diatas pastia akn berputar ke bawah, atau sebaliknya, dari bawah akan berputar hingga sampai di atas. Nampaknya demikianlah yang sedang dihadapi oleh perusahaan Nokia.

Perjalanan panjang Nokia sangat dramatis, Nokia yang dulunya sangat terkenal dengan semboyan," ponsel sejuta umat," akhirnya harus merelakan mundur dari pertarungan pasar setelah Samsung Electronics Co Ltd akan menjadi pembuat ponsel pintar terbesar pada kuartal ini.Nokia tercatat masih memegang tampuk pimpinan dalam hal penjualan ponsel secara global. Namun, posisi Nokia tersebut ditengarai belum aman, mengingat vendor mapan lain seperti Apple, RIM, dan Google lewat Android-nya diketahui getol mengeluarkan jurus baru untuk memikat konsumen. 


\section{E. DISKUSI}

Bagas:apa yang kamu ketahui tentang sejarah nokia.

Pathul:semakin berkembang dari masa ke masa.

Komar:bagaimana perkembangan nokia saat ini.

Risky:semakin membaik dan semakin canggihs

\section{F. REFERENCE}

[1] O. M. Febriani and A. S. Putra, "Sistem Informasi Monitoring Inventori Barang Pada Balai Riset Standardisasi Industri Bandar Lampung," J. Inform., vol. 13, no. 1, pp. 90-98, 2014.

[2] A. S. Putra, "Paperplain: Execution Fundamental Create Application With Borland Delphi 7.0 University Of Mitra Indonesia," 2018.

[3] A. S. Putra, "2018 Artikel Struktur Data, Audit Dan Jaringan Komputer," 2018.

[4] A. S. Putra, "ALIAS MANAGER USED IN DATABASE DESKTOP STUDI CASE DB DEMOS."

[5]

A. S. Putra, "COMPREHENSIVE SET OF PROFESSIONAL FOR DISTRIBUTE COMPUTING."

[6] A. S. Putra, "DATA ORIENTED RECOGNITION IN BORLAND DELPHI 7.0."

[7] A. S. Putra, "EMBARCADERO DELPHI XE 2 IN GPUPOWERED FIREMONKEY
APPLICATION."

[8] A. S. Putra, "HAK ATAS KEKAYAAN INTELEKTUAL DALAM DUNIA TEKNOLOGY BERBASIS REVOLUSI INDUSTRI 4.0."

[9] A. S. Putra, "IMPLEMENTASI PERATURAN

PERUNDANGAN UU. NO 31

TAHUN 2000 TENTANG DESAIN INDUSTRI BERBASIS INFORMATION TECHNOLOGY."

[10]

A. S. Putra, "IMPLEMENTATION OF PARADOX DBASE."

[11] A

S. Putra, "IMPLEMENTATION OF TRADE SECRET CASE STUDY SAMSUNG MOBILE PHONE."

[12] A. S. Putra, "IMPLEMENTATION PATENT FOR APPLICATION WEB BASED CASE STUDI WWW. PUBLIKLAMPUNG. COM."

[13] A S. Putra, "IMPLEMENTATION SYSTEM FIRST TO INVENT IN DIGITALLY INDUSTRY."

[14] A. S. Putra, "MANUAL REPORT \& INTEGRATED DEVELOPMENT ENVIRONMENT BORLAND DELPHI 7.0."

[15] A. S. Putra, "PATENT AS RELEVAN SUPPORT RESEARCH."

[16] A. S. Putra, "PATENT FOR RESEARCH STUDY CASE OF APPLE. Inc."

[17] A. S. Putra, "PATENT PROTECTION FOR APPLICATION INVENT."

[18] A. S. Putra, "QUICK REPORT IN

PROPERTY 
PROGRAMMING."

[19] A. S. Putra, "REVIEW CIRCUIT LAYOUT COMPONENT REQUIREMENT ON ASUS NOTEBOOK."

[20] A. S. Putra, "REVIEW TRADEMARK PATENT FOR INDUSTRIAL TECHNOLOGY BASED 4.0."

[21] A. S. Putra, "TOOLBAR COMPONENT PALLETTE IN OBJECT ORIENTED PROGRAMMING."

[22] A. S. Putra, "WORKING DIRECTORY SET FOR PARADOX 7."

[23] A. S. Putra, "ZQUERY CONNECTION

IMPLEMENTED

PROGRAMMING STUDI CASE PT. BANK BCA Tbk."

[24] A. S. Putra, D. R. Aryanti, and I. Hartati, "Metode SAW (Simple Additive Weighting) sebagai Sistem Pendukung Keputusan Guru Berprestasi (Studi Kasus: SMK Global Surya)," in Prosiding Seminar Nasional Darmajaya, 2018, vol. 1, no. 1, pp. 85-97.

[25] A. S. Putra and O. M. Febriani, "Knowledge Management Online Application in PDAM Lampung Province," in Prosiding International conference on Information Technology and Business (ICITB), 2018, pp. 181-187.

[26] A. S. Putra, O. M. Febriani, and B. Bachry, "Implementasi Genetic Fuzzy System Untuk Mengidentifikasi Hasil Curian Kendaraan Bermotor $\mathrm{Di}$ Polda Lampung," SIMADA (Jurnal Sist. Inf. dan Manaj.
Basis Data), vol. 1, no. 1, pp. 21-30, 2018.

[27] A. S. Putra, H. Sukri, and K. Zuhri, "Sistem Monitoring Realtime Jaringan Irigasi Desa (JIDES) Dengan Konsep Jaringan Sensor Nirkabel," IJEIS (Indonesian J. Electron. Instrum. Syst., vol. 8, no. 2, pp. 221-232.

[28] D. P. Sari, O. M. Febriani, and A. S. Putra, "Perancangan Sistem Informasi SDM Berprestasi pada SD Global Surya," in Prosiding Seminar Nasional Darmajaya, 2018, vol. 1, no. 1, pp. 289-294. 